\title{
TURISMO RURAL E ECOTURISMO EM SÃO JOSÉ DOS AUSENTES / RS ${ }^{1,2}$
}

Grupo PET-Geografia ${ }^{3}$

\section{Resumo}

Neste artigo procuramos discutir os conceitos que envolvem o ecoturismo, utilizando como estudo de caso o município de São José dos Ausentes. Procuramos entender, através da realização de entrevistas, a visão da população local sobre o ecoturismo, assim como a importância que esses vêem do mesmo, o papel das políticas públicas e a relação dos turistas com a cidade; buscando verificar a viabilidade do ecoturismo para a realidade local. Também a tentativa de identificação do município como referencial para o desenvolvimento dessa atividade a partir de uma análise conceitual, relacionando às potencialidades de São José dos Ausentes.

Palavras-Chave: ecoturismo, turismo rural, desenvolvimento regional.

\section{Caracterização da área de estudo}

O município de São José dos Ausentes está situado no extremo nordeste do Rio Grande do Sul, na região das Hortências - Campos de Cima da Serra ${ }^{3}$. A uma distância de $270 \mathrm{~km}$ de Porto Alegre e com coordenadas de $28^{\circ} 44^{\prime} 54^{\prime \prime} \mathrm{S}$ e $50^{\circ} 03^{\prime} 57^{\prime \prime} \mathrm{W}$, o município limita-se a norte e nordeste com o Estado de Santa Catarina, a sul com o município de Cambará do Sul, a sudoeste com o município de Jaquirana e a oeste com o município de Bom Jesus.

\footnotetext{
${ }^{1}$ Pesquisa

${ }^{2}$ Artigo publicado no CITURDES.

${ }^{3}$ Ana Stumpf Mitchell; Daniel Mallmann Vallerius; Éverton de Moraes Kozenieski; Fábio Guadagnin; Felipe Velho Azevedo Costa; Fernando Dreissig de Moraes; Graziela Bohusch; Heitor Alexandre Brandão Jr; Judeci da Silva; Karen Aline Heberle; Matheus Hainzenreder Schaf; Neudy Alexandro Demichei; Rafael Zilio Fernandes; Renata Ferreira Da Silveira; Rodrigo Bennett; Tiago Bassani Rech; Tiago Oliveira Nicoloso; Rosa Maria Vieira Medeiros.
} 
Fig. 1: Localização do município de São José dos Ausentes.

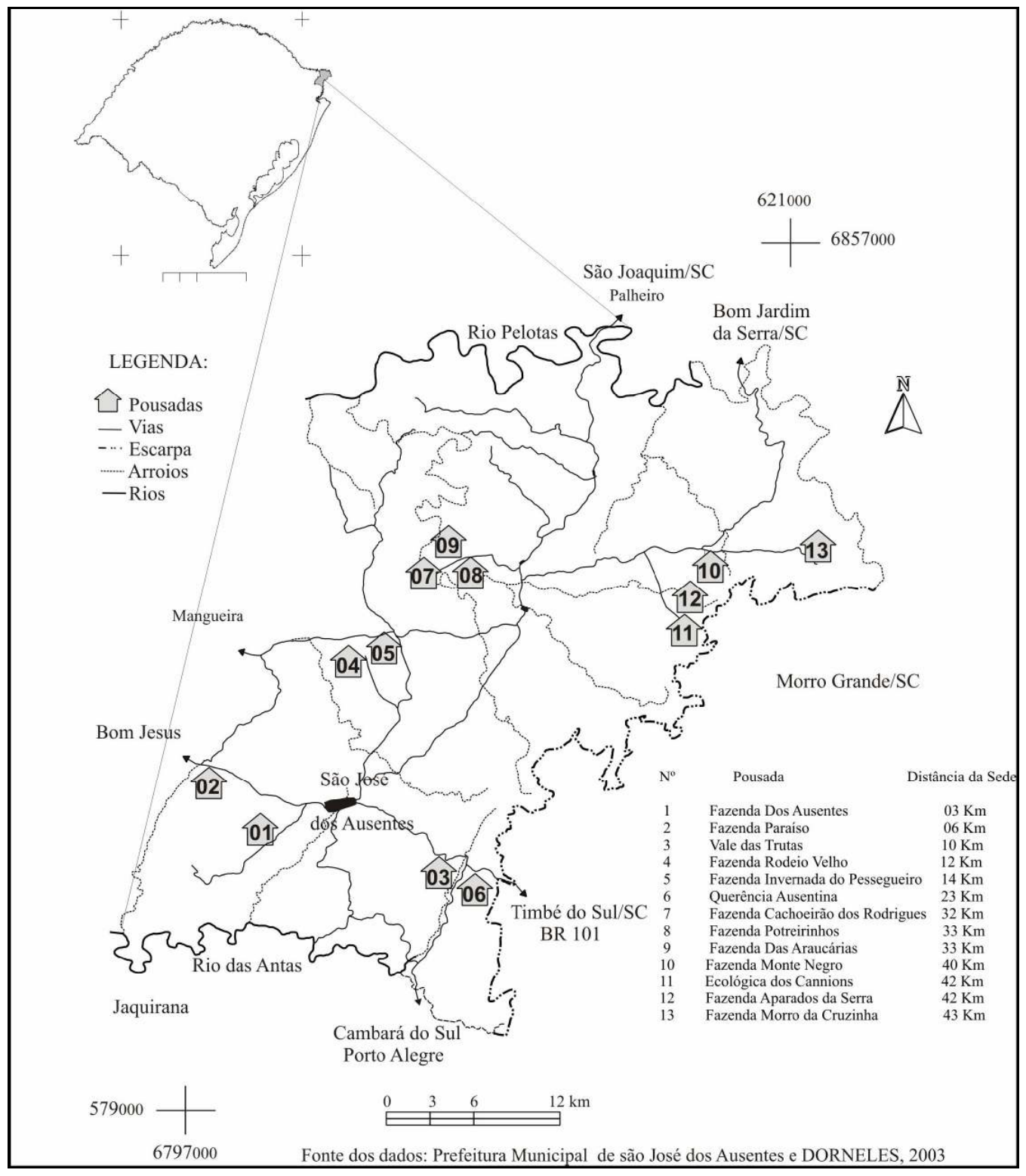

Fonte: PETGEA/UFRGS

\section{Histórico do Município}

A história conta que a Fazenda dos Ausentes foi o maior latifúndio do Rio Grande do Sul, com uma área de mais de $1.000 \mathrm{~km}^{2}$. Seus primeiros donos, ainda no século XVIII, não assumiram as terras, que acabaram leiloadas duas vezes pela ausência de proprietários ou de sucessores - não por acaso, esse pedaço de Campos de Cima da Serra foi batizado de Ausentes. Hoje, o município de 3.100 habitantes vive da pecuária extensiva, do cultivo de batata e maçã, do florestamento/reflorestamento e do turismo rural (BOECHAT, 2001, P. 15).

No século XVIII, a Coroa Portuguesa decidiu que seria necessário haver uma ligação entre a Colônia de Sacramento e o centro do Brasil. Desta forma, algumas regiões até então inóspitas precisavam ser ocupadas: estava aberto o caminho dos tropeiros, homens que 
cavalgavam do sul ao centro do Brasil, levando consigo o gado xucro (não domado). A coroa portuguesa designou o sargento-mor Francisco de Souza e Faria para a função de “desbravador" da região. Em 1729, o sargento-mor parte da Barra do rio Araranguá e chega ao topo dos Aparados da Serra Geral, atualmente conhecida como os Campos de Cima da

Serra. Posteriormente, foi concedido o direito de posse dessas terras a serem ocupadas a posseiros nomeados pela coroa, porém, os três primeiros posseiros abandonaram a sesmaria. Sem dono, as terras foram declaradas bens de ausentes e vendidas em leilão público. $\mathrm{O}$ capitão que as arrematou nunca residiu no local e quando morreu, não deixou descendentes, nem testamento. A fazenda, mais uma vez, foi a leilão em Juízo de Ausentes. Irremediavelmente, o lugar passou a ser chamado de Querência dos Ausentes.

A fazenda teve ainda outros dois donos. Por fim, eles a venderam a Manuel Antônio Velho, em 1887. Este português deu início à fazenda dos Ausentes, que chegou a ser o maior latifúndio do Rio Grande do Sul, com mais de $1.000 \mathrm{~km} 2$. Próximo à fazenda foi construída uma capela em homenagem a São José no ano de 1940. A partir daí o nome da região passou a ser São José dos Ausentes.

A partir de 1993, ao emancipar-se de Bom Jesus, o município de São José dos Ausentes despertou para o turismo, buscando uma nova forma de renda e de desenvolvimento econômico.

\section{Caracterização do Município}

São José dos Ausentes é um município peculiar por ser rico em paisagens naturais como os cânions e o Pico do Monte Negro, ponto de maior altitude do RS; quedas d'água, como o Cachoeirão dos Rodrigues; além do clima com baixas temperaturas próprias da região dos Campos de Cima da Serra. Outra característica marcante é a abundância de rios, arroios e cascatas que cruzam capões; as araucárias predominam na vegetação local, assim como musgos coloridos em matas que destoam na paisagem.

O ecoturismo passou a ser estimulado pela prefeitura municipal, após sua emancipação. As pousadas das famílias que moram na região foram somadas às paisagens de campos, desse modo, essas pousadas passaram a configurar um outro ponto fundamental para que os visitantes possam encontrar o estilo de vida presente no imaginário relacionado ao espaço rural, marcado pela visão do interior como um lugar isolado do mundo urbano. 


\section{Metodologia}

Um trabalho de campo foi realizado em São José dos Ausentes, nos dias 24 e 25 de maio de 2005. Um total de vinte entrevistas junto a donos de pousadas, estabelecimentos comerciais, moradores e turistas foi aplicada. Os questionários tiveram caráter qualitativo com questões semi-abertas. Encerrando com uma breve revisão bibliográfica acerca dos conceitos de ecoturismo, turismo rural e turismo em áreas rurais. Em seguida, a tabulação dos dados foram cruzados com o referencial teórico para provar o objetivo desta pesquisa.

\section{Ecoturismo e capitalismo}

O último século foi marcado pela expansão e consolidação do capitalismo, enquanto regime político-econômico predominante no mundo. Com a rápida troca de informações via Internet iniciou-se a globalização. O capital tende a se concentrar de diferentes formas e nessa busca competitiva de realização da nova fase há uma aposta crescente nas atividades turísticas. O turismo entra como um fenômeno econômico e social que movimenta grande contingente de pessoas e um alto volume de capital, sendo capaz de dinamizar significativos setores produtivos dos mais diferentes lugares do mundo, sendo também um dos mais notáveis agentes promotores da reorganização do espaço.

A atividade econômica mundial, baseada na produção de massa e no consumismo, acaba definindo e impondo estilos e comportamentos que interferem diretamente na qualidade de vida da população. Essa situação se expressa através das tendências e preferências de consumo, no caso dos grandes centros urbanos a questão qualidade de vida é considerada uma demanda crescente.

Dentro deste cenário é que surgiu o chamado marketing verde, produtos e serviços direcionados a um segmento específico que valoriza e consome produtos ecologicamente corretos. Surge então o ecoturismo, uma nova forma de turismo que cresceu nos últimos anos.

É importante ressaltar que não podemos confundir turismo rural com ecoturismo, que por sua vez pode ser em área rural. Turismo rural é quando o turista busca aprender alguma coisa culturalmente, convivendo e participando das atividades diárias com os moradores locais, e ecoturismo é a interação com a natureza em ambientes que podem ser rurais.

Tratando-se de lidar com a natureza, o ecoturismo deve ter alguns limites para não degradá-la. A limitação do número de ecoturistas em certas áreas, por exemplo, ajudaria na conservação do ambiente. 
Para Amâncio \& Gomes ${ }^{4}$,

(...) discutir ecoturismo e desenvolvimento sustentável é um desafio interessante, principalmente quando se tenta descaracterizar a atividade ecoturística de um estigma elitista. Ver o ecoturismo como uma atividade a ser trabalhada ou 'explorada' por grupos capitalizados financeiramente é reduzir seu papel como elemento importante para promover o desenvolvimento rural $\mathrm{e}$ incluir segmentos da população que são historicamente marginalizados do acesso a mecanismos de produção na sociedade capitalista, sejam eles materiais ou de caráter social e cultural ( $p$ 139).

O ecoturismo nasceu no campo das discussões ecológicas, sendo evidenciado na Rio 92, porém, de acordo com Furlan (2003), transformando-se em mais de uma das respostas do setor produtivo às pressões sociais para a conservação ambiental. O ecoturismo, uma atividade também comercial, leva em seu arcabouço os fatores que este tipo de atividade implica (impactos socioambientais diversos). Dentro desta óptica, surge o ecoturista, que trata de forma consciente o espaço com que se relaciona. Uma diferenciação entre turismo em áreas rurais e turismo rural é necessária.

O ecoturismo pode ser entendido como uma forma de desfrutar visitas a áreas naturais, promovendo, ao mesmo tempo, sua conservação e apelando para o envolvimento das populações locais (CONTI, 2003). Por sua vez,

o turismo rural, que parte do ecoturismo, estaria relacionado a atividades agrárias passadas e presentes que conferem à paisagem sua fisionomia nitidamente rural, diferenciando-se das áreas cuja marca persistente é o grau de maturidade, relativo a ecossistemas ricos em biodiversidade (...) (RODRIGUES, 2000:54-55).

Numa questão híbrida entre ambos, tem-se o turismo eco-rural. Além disso. esse tipo de turismo pressupõe um contato com o ambiente rural e que tenha uma inter-relação com a sociedade local (CALVENTE, 2005:13).

Diante deste quadro sobre o turismo rural / eco-rural, é necessário observar o papel de um ator fundamental: o turista. O turista é o consumidor do turismo, portanto, ele busca requisitos mínimos no pacote adquirido. De acordo com Steil (2002:65),

os turistas não consomem lugares ou 'olhares', mas através dos lugares e dos olhares buscam a realização de um desejo que transcende e povoa sua imaginação". Neste ínterim consumista, o ideal seria o sujeito ecológico, que compartilha freqüentemente a mesma filosofia do ecoturista, portadores da idéia de que é preciso mudar a lógica nas sociedades contemporâneas se quisermos conservar a natureza e praticar a eqüidade social (FURLAN, 2003, p. 50).

\footnotetext{
4 apud Goulart, 2001.
} 
Portanto, esse sujeito depende de atitudes, compromissos e responsabilidades. Essas atitudes podem ser encontradas no ecoturismo e suas ramificações, onde há, ou deveria haver, uma preocupação maior para com a natureza, visto que o ecoturismo é usado como fuga do caos das grandes cidades, costumeiramente.

Então, percebendo-se esta brecha de mercado, o turismo rural está cada vez mais presente nas fazendas ou nas pequenas propriedades de regiões tipicamente rurais em São José dos Ausentes, pois

(...) as idéias construídas sobre o quotidiano no campo, o contacto com a natureza e as culturas tradicionais traduzem-se numa revalorização do rural e do local e induzem uma busca singular, do específico, do autêntico. O espaço rural ganha, por este meio, um crescente valor simbólico e assume uma legitimidade diferente da legitimidade alimentar do passado (...) (CRISTÓVÃO, 2002, p. 85).

É a representação dos campos como locais de liberdade, beleza, segurança e saúde, de pertença e enraizamento. Ao espaço rural passam a ser reconhecidas funções mais diversificadas do que a simples produção de alimentos.

Frente a estas novas funções que o campo adquiriu, está o turismo, sendo o ecoturismo empregado como alternativa de renda quando a propriedade não tem condições de subsistir das funções agrárias.

\section{O caso de São José dos Ausentes e considerações}

A Prefeitura Municipal, através do secretário de turismo, cultura, desenvolvimento e meio ambiente de São José dos Ausentes5, mostra-se bastante interessada no desenvolvimento das atividades de ecoturismo. Além de ser uma forma de minimizar o êxodo rural, é uma fonte de renda alternativa às famílias. No município são praticados, segundo o secretário, turismo rural e ecológico. O "e" é muito importante pois significa a existência do turismo rural e do turismo ecológico, mas o turismo rural não é sempre ecológico, como o caso da Fazenda de Faisões (do tipo cace e pague). No município existem 500 leitos e as pousadas estão organizadas em uma associação denominada IGRE, que significa, em tupiguarani, "amigos da água".

Ecoturismo é considerado pela Prefeitura "um turismo que se pratica na natureza", dotado de sustentabilidade pois as pessoas vivem do turismo (muitas vezes a única atividade econômica). Como pontos negativos do desenvolvimento do ecoturismo, foi levantada a

\footnotetext{
${ }^{5}$ Em entrevista realizada dia 24 de maio de 2005.
} 
depredação do meio ambiente: "os turistas não têm noção do meio ambiente, eles acham que eles são no campo e que lá não tem problemas de poluição. Degradação do meio ambiente mesmo com orientação; o turista não é educado, levam as pedras, barba-de-pau, flores e deixa o lixo; as pessoas que trabalham são orientadas".

O desenvolvimento do ecoturismo iniciou-se com as famílias das pousadas com ajuda e organização da Secretaria, através de uma adaptação dos espaços já existentes. A Secretaria escolheu as fazendas que apresentavam um perfil para serem transformadas em pousadas e que estivessem localizadas em pontos considerados turísticos. As pousadas trabalham de forma independente em relação às agências de turismo e isso é importante para a Secretaria: manter a independência e a sustentabilidade. Atualmente $10 \%$ da população trabalha com o turismo, segundo o secretário "a cidade não respira o turismo".

O Programa Selo de Qualidade do Município confere esse selo às pousadas que obedecem alguns critérios estabelecidos pelo município, entre eles exames de saúde para pessoas que trabalham e segurança alimentar. A citada Secretaria também funciona como acessória de imprensa. A Faculdade de Biblioteconomia e Comunicação (FABICO) da UFRGS é uma importante parceria na divulgação do município, através do curso de fotografia ambiental.

No estudo presente, verificamos que a intervenção do estado foi um dos principais mecanismos objetivando a consciência do aproveitamento turístico da região por parte da população local, uma vez que a produção rural tem passado por um período de estagnação econômica.

Impulsionados pelas políticas públicas, os trabalhadores rurais começaram a investir no setor turístico, principalmente na área de pesca e contemplação da natureza ${ }^{6}$. De acordo com a proprietária da pousada-fazenda Aparados da Serra, Elizabete Vieira, onde esta diz que “os principais pontos visitados são o Pico do Monte Negro e o Cachoeirão dos Rodrigues". Segundo a mesma, um significativo número de turistas "vem para a pousada para relaxar". Ou seja, existem turistas que freqüentam São José dos Ausentes que não estão diretamente preocupados com o modo de vida do campo, realizando uma forma de turismo contemplativo. Neste caso, o que acontece é a busca de descanso pelo turista, não sendo efetivamente turismo rural. No entanto, esse estabelecimento diverge dos demais, uma vez que é uma pousadafazenda, enquanto que a maioria das demais são fazendas-pousadas.

Segundo Silva e Baldan apud Silva,

\footnotetext{
${ }^{6}$ Em São José dos Ausentes é possível encontrar rios de águas límpidas e para boa pesca (Rio Divisa, Rio das Antas), além do ponto mais alto do estado (Monte Negro).
} 
A fazenda-hotel [no nosso caso fazenda-pousada] está voltada para uma clientela cada vez mais carente de contato com o cotidiano da Terra, com a rotina de um modo de vida que, pelo menos no imaginário urbano, remete a uma reconciliação com a natureza. (...) A característica básica desses empreendimentos é que as fazendas continuam produtivas. Além de andar a cavalo, contemplar paisagens e praticar esportes, os hóspedes podem vivenciar rotinas que vão desde a ordenha à alimentação do gado, o trato dos suínos e as colheitas. Um ingrediente que instiga, seduz e informa. (1998, p. 139).

Neste caso, os turistas colocam o conforto em segundo lugar, priorizando a autenticidade das relações de vida do espaço rural. Isso significa dizer que o turista busca aprender alguma coisa, propicia uma busca de símbolos e imagens deste ambiente, saindo o turista enriquecido culturalmente.

O turista que procura o ambiente rural com este objetivo está realizando o turismo rural e não o turismo em áreas rurais, como aqueles que buscam uma pousada apenas para descansar, não interagindo com o ambiente.

Turismo Rural $\neq$ Turismo em áreas rurais $=$ Turismo Contemplativo.

Porém, a particularidade que chama atenção em São José dos Ausentes é a consciência ambiental que os proprietários das fazendas-pousadas, preocupando-se primeiramente com a preservação e manutenção dos ecossistemas, pois como os próprios proprietários mencionaram, "se não preservarmos a natureza, o turismo não fará mais sentido". Baseado nisso, é importante discorrer que o ecoturismo vêm a ser uma fonte de renda extra a propriedade rural, uma nova função, continuando porém com suas atividades agropecuárias. As atividades agropecuárias são de muita importância para o turismo rural, uma vez que o turista acaba tendo contato com instrumentos culturais diferentes ao seu espaço de vida. No estudo de caso, quase que a totalidade de turistas provém de áreas cosmopolitas, com hábitos, costumes e atividades diferentes das vivenciadas no local. Outro ponto é a presença de turistas de outros Estados, como um casal de turistas de São Paulo. Quando perguntados sobre o porquê deles escolherem São José dos Ausentes, esses foram enfáticos: “moro em São Paulo, capital. Ou seja, muito agitada, estressante e aqui você encontra sossego, sai da rotina".

Outra característica interessante está relacionada aos locais que visitaram e atividades que realizaram: cavalgada no Desnível, Cachoeirão dos Rodrigues, todos os pontos turísticos, exceto a sede do município. 
Sobre as transformações sócio-econômicas e espaciais que o ecoturismo trouxe à região, podemos dizer que esta atividade tem movimentado a economia local, principalmente nas áreas rurais. Pois como diz Dinarci Araújo, proprietário da Pousada das Araucárias, houve "um melhoramento da qualidade da vida, melhoramento das estradas,melhoramento dos serviços e infra-estruturas para os habitantes".

Concomitante ao aumento da procura de turistas por São José dos Ausentes, o aumento de empregos encontra-se restrito à inserção de familiares nos trabalhos de manutenção das pousadas, onde os filhos que estudam nos municípios próximos retornam nos fins de semana para auxiliar nos trabalhos com os turistas. Ou seja, o trabalho familiar, com poucos empregados, preserva a estrutura das fazendas e a identidade cultural da região, temática apreciada por alguns turistas, mas não de forma unânime.

A implantação do ecoturismo trouxe a São José dos Ausentes uma nova atividade econômica, intrínseca às atividades agropecuárias existentes, levando o município à mídia nacional - caso da mini-série "A Casa das Sete Mulheres", editada pela Rede Globo impulsionando a atividade econômica local, porém, respeitando uma das finalidades do ecoturismo, que é o aumento da preservação do meio ambiente.

\section{Referências bibliográficas}

BAIARDI, Amílcar. Neoprodutivismo, neoassociativismo e turismocampestre: outras faces do novo rural. Salvador, Caderno RCH UFBa, 1998:11-26.

CALVENTE, Maria del Carmen Matilde Huertas. Turismo e excursionismo rural: potencialidades, regulação e impactos. Londrina, Edições Humanidades, 2004.

CRISTÓVÃO, Artur, In RIEDL, Mário, ALMEIDA, Joaquim Anécio, VIANA, Adriana Lima Barbosa (org.). Turismo rural: tendências e sustentabilidade. Santa Cruz, Edusc, 2002:81-116.

DORNELES, Álvaro Conforte. Turismo Rural-ecológico em São José dos Ausentes / RS com ênfase em desenvolvimento local. Monografia (graduação) Instituto de Geociências, curso de Geografia, UFRGS, Porto Alegre, 2003.

FURLAN, Sueli Ângelo. In: RODRIGUES, Edyr Balesteri (org.). Ecoturismo no Brasil: possibilidades e limites. São Paulo, Contexto, 2003:47-58.

GOULART, Ézio Dornela. Ecoturismo e Desenvolvimento Sustentável. Disponível em www.ecoviagem.com.br/ecoartigos/def_ecoartigos.asp?codigo=4736. Acesso em 13 de agosto de 2005 . 
GRAZIANO DA SILVA, José, VILARINHO, Carlyle, DALE, Paul J. Turismo em áreas rurais: suas possibilidades e limitações no Brasil. Salvador, Caderno RCH UFBa, 1998:113-155.

STEIL, Carlos Alberto. In: RIEDL, Mário, ALMEIDA, Joaquim Anécio, VIANA, Adriana Lima Barbosa (org) Turismo rural: tendências e sustentabilidade. Santa Cruz, Edusc, 2002:51-80. 